\title{
DESAIN ORGANISASI DINAS PERHUBUNGAN, KOMUNIKASI DAN INFORMATIKA KABUPATEN BANDUNG BARAT
}

\author{
Tika Kartika Asri \\ Dosen Program Studi Manajemen, STIE Dewantara \\ Jl. Raya Pemda Bojong Depok Baru III, Karadenan, Cibinong, Bogor, Jawa Barat 16913, Indonesia \\ Email: asrikartikatika@gmail.com
}

\begin{abstract}
This research aims to determine how the organizational design of Department of Transportation, Communication and Information in West Bandung Regency. Hellriegel and Slocum, there are have six elements such as task, technology, strategic, design, culture, and people. The researcher using qualitative methods with collection of data technique by library research, observation and interview. Informants on this research were selected based on purposive technique with sampling data and consideration. Data analysis is start from data reduction, data presentation, and conclusions. The results implementation of organizational design at Department of Transportation, Communication and Information in West Bandung Regency yet optimally, because there's some aspects that have not been fulfilled. The problem solving from the researcher is restructure the design organization at Department of Transportation, Communication and Information in West Bandung Regency. Government have to consideration to merge between transportation field with communication and information filed, cause both of them have different function, role and job to achieve the purpose in West Bandung Regency.
\end{abstract}

Keywords: Design Organization, Transportation, Communication and Information, West Bandung Regency.

ABSTRAK
Peneliti tertarik untuk menganalisis desain organisasi yang telah berubah di Dina Perhubungan, Komunikasi, dan Informasi. Penelitian ini bertujuan untuk mengetahui bagaimana desain organisasi Dinas Perhubungan, Komunikasi dan Informasi di Kabupaten Bandung Barat. Teori yang didasarkan pada penelitian ini adalah perubahan sistemik oleh Hellriegel dan Slocum, ada enam elemen seperti tugas, teknologi, strategi, desain, budaya dan manusia. Peneliti menggunakan metode kualitatif dengan teknik pengumpulan data dengan studi pustaka, observasi dan wawancara. Informan pada penelitian ini dipilih berdasarkan teknik purposive dengan pengambilan sampel data dan pertimbangan. Analisis data dimulai dari reduksi data, penyajian data, dan penarikan kesimpulan. Hasil implementasi desain organisasi pada Dinas Perhubungan, Komunikasi dan Informasi di Kabupaten Bandung Barat belum optimal, karena ada beberapa aspek yang belum terpenuhi. Pemecahan masalah dari peneliti adalah merestrukturisasi organisasi desain di Dinas Perhubungan, Komunikasi dan Informasi di Kabupaten Bandung Barat. Pemerintah harus mempertimbangkan untuk menggabungkan antara bidang transportasi dengan komunikasi dan informasi yang diajukan, karena keduanya memiliki fungsi, peran dan pekerjaan yang berbeda untuk mencapai tujuan di Kabupaten Bandung Barat.

Kata kunci: Desain Organisasi, Perhubungan, Komunikasi dan Informatika, Kabupaten Bandung Barat.

\begin{tabular}{|c|c|}
\hline PENDAHULUAN & Perubahan-perubahan \\
\hline Latarbelakang & yang terjadi akan berdampak kepada \\
\hline Perubahan organisasi & aspek-aspek \\
\hline proses yang berkesinambungan karena & organisasi untuk mencapai tujuannya. \\
\hline organisasi selalu menghadapi tuntutan & organisasi \\
\hline $\begin{array}{l}\text { lingkungan interal maupun eksternal } \\
\text { organisasi. }\end{array}$ & $\begin{array}{l}\text { pemerintah, mendesain struktur organisasi } \\
\text { pemerintahan membutuhkan perhatian }\end{array}$ \\
\hline
\end{tabular}


yang khusus karena organisasi ini bersifat formal. Struktur organisasi pemerintahan pun mencakup berbagai peraturan, wewenang serta pembagian tugas yang kompleks. Untuk itu dalam melakukan desain organisasi pemerintahan harus memperhatikan pengelompokan sumber daya sesuai dengan kompetensi, wewenang, dan pembagian tugas berdasarkan aturan yang ada agar koordinasi dalam organisasi dapat terjalin dengan baik.

Di dalam Peraturan Pemerintah No.41 tahun 2007 tentang Organisasi Perangkat Daerah menjelaskan bahwa terdapat keseriusan pemerintah menciptakan penyelenggaraan pemerintahan yang lebih baik sejak pemberlakuan Undang-Undang Nomor 23 Tahun 2014 tentang Pemerintahan Daerah, yang diharapkan dapat memberikan arahan dan pedoman yang jelas kepada daerah.

Dinas Daerah Kabupaten Bandung Barat dibentuk berdasarkan Peraturan Daerah Kabupaten Bandung Barat Nomor 3 Tahun 2012 Tentang Organisasi Perangkat Daerah. Sesuai dengan Peraturan Daerah Kabupaten Bandung Barat Nomor 3 Tahun 2012 terdapat salah satu dinas yaitu Dinas Perhubungan, Komunikasi dan Informatika. Dinas tersebut mempunyai tugas pokok yaitu melaksanakan urusan pemerintahan daerah di bidang Perhubungan, Komunikasi, dan Informatika berdasarkan asas otonomi dan tugas pembantuan.

Dinas Perhubungan, Komunikasi dan Informatika Kabupaten Bandung Barat mempunyai peranan yang penting salah satunya yaitu memfasilitasi penyelenggaraan program pembangunan dalam pelayanan di bidang lalu lintas, angkutan, teknis sarana dan prasarana, komunikasi dan informatika.

Salah satu perubahan organisasi yang dialami adalah perubahan struktur. Hal tersebut merupakan respon akan kehadiran Peraturan Pemerintah No.41 tahun 2007 yang dirasa Dinas Perhubungan, Komunikasi dan Informatika memiliki penggabungan sesuai dengan perumpunan urusan pemerintahan yang dikelompokkan maupun menjawab peran Komunikasi dan Informatika sebagai salah satu hal penting dalam menciptakan lahirnya reformasi birokrasi yaitu e-goverment.

Perkembangan lingkungan yang semakin dinamis serta urusan Dinas Perhubungan, Komunikasi dan Informatika yang semakin meluas dan jauh berbeda, menimbulkan wacana adanya pemisahan antara bidang perhubungan dengan komunikasi dan informatika. Nomenklatur perhubungan dan komunikasi dan informatika tidak bisa disamakan, bahkan penggabungan ini menjadi persoalan karena peran perhubungan lebih dominan dibandingkan komunikasi dan informatika. Sehingga perubahan desain organisasi yang dilakukan Dinas Perhubungan menjadi Dinas Perhubungan, Komunikasi dan Informatika Kabupaten Bandung Barat menjadi kurang tepat apabila melihat perkembangan lingkungan yang terjadi.

\subsection{Rumusan Masalah}

Berdasarkan latar belakang yang telah diuraikan, maka penulis mengidentifikasikan permasalahannya yaitu

1. Bagaimana Desain Organisasi setelah terjadi penggabungan antara Bidang Perhubungan dan Bidang Komunikasi dan Informatika di Kabupaten Bandung Barat?

\subsection{Tujuan Penelitian}

Mendeskripsikan bagaimana desain organisasi setelah terjadi penggabungan antara bidang Perhubungan dengan bidang Komunikasi dan Informatika di Kabupaten Bandung Barat.

\section{TINJAUAN PUSTAKA}

\subsection{Landasan Teori}

Hellriegel dan Slocum (1998:581) 
menjelaskan bahwa systems model of change is a model that describes the organization as six interacting variables (people, culture, task, technology, design, and strategy) that could serve as the focus of planned change.

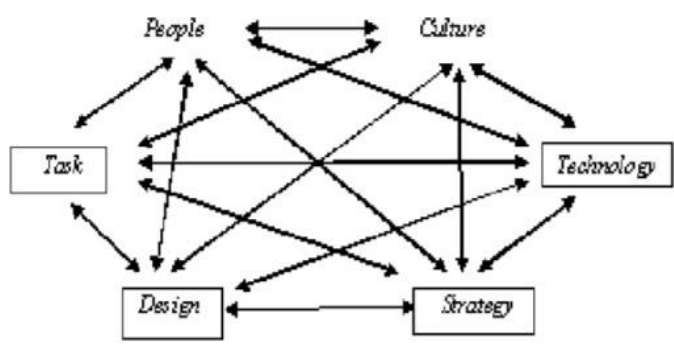

Gambar 1. 6 Elemen Model Perubahan

Sumber : Hellriegel dan Slocum (2007:457)

Sesuai pada gambar diatas, terdapat penjelasan dari masing-masing variabel tersebut dengan sebagai berikut :

\section{Task}

Variable that involves the nature of the work itself-whether jobs are simple or complex, novel or repetitive, standardized or unique.

\section{Technology}

Variable that encompasses the problem-solving methods and techniques used and the application of knowledge to various organizational processes.

3. Strategic

Variable that comprises the organization's planning process and includes decisions about how the organization chooses to compete.

4. Design

In the systems model of change, the variable that pertains to the formal organizational structure and its systems of communication, control, authority, and responsibility.

5. Culture

Shared beliefs, values, expectations, and norms of organizational members.

\section{People}

The individuals working for the organization, including their individual differences-personalities, attitudes, perceptions, attributions, needs, and motives. (Faria Ruhana, 2009:79).

\section{METODE PENELITIAN}

\subsection{Metode Penelitian}

Pada penelitian ini peneliti menggunakan metode kualitatif, karena untuk menggambarkan atau menjelaskan suatu hal yang kemudian dikasifikasikan sehingga dapat diambil satu kesimpulan. Kesimpulan tersebut dapat lebih mempermudah dalam melakukan penelitian dan pengamatan.

\subsection{Teknik Pengumpulan Data}

Pada penelitian ini penulis menggunakan metode kualitatif, karena untuk menggamabarkan atau menjelaskan suatu hal yang kemudian diklasifikasikan sehingga dapat diambil satu kesimpulan. Data yang diperoleh dalam penelitian ini berasal dari studi keputusan (library research), yang meliputi observasi dan wawancara.

\subsection{Teknik Penentuan Informan}

Informan dalam penelitian ini dipilih berdasrkan teknik purposive yaitu teknik pengambilan sampel sumber data dengam pertimbangan :

1. Otoritas yang dimiliki oleh informan dalam kaitan dengan desain organisasi Dinas Perhubungan Komunikasi dan Informasi Kabupaten Bandung Barat

2. Dianggap memiliki informasi yang banyak mengenai desain organisasi Dinas Perhubungan Komunikasi dan Informasi Kabupaten Bandung Barat

3. Memiliki keterkaitan, baik secara individu maupun institusi, desain organisasi Dinas Perhubungan Komunikasi dan Informasi Kabupaten Bandung Barat. 
Oleh karena itu, penelitian ini terbagia atas 7 informan, yaitu:

1. Sekretaris Dinas,

2. Kepala Sub Bagian Kepegawaian dan Umum,

3. Kepala Sub Bagian Program Bidang Lalu Lintas,

4. Kepala Sub Bagian Bidang Angkutan,

5. Kepala Sub Bagian Bidang Teknik Sarana dan Prasarana,

6. Kepala Sub Bagian Bidang Komunikasi dan Informatika.

\section{HASIL DAN PEMBAHASAN}

Perubahan desain organisasi Dinas Perhubungan menjadi Dinas Perhubungan, Komunikasi dan Informatika Kabupaten Bandung Barat merupakan tanggapan atas adanya Peraturan Pemerintah No.41 Tahun 2007 tentang Organisasi Perangkat Daerah. Dimana dalam peraturan pemerintah tersebut Dinas Perhubungan, Komunikasi dan Informatika memiliki penggabungan sesuai dengan perumpunan urusan pemerintahan yang dikelompokkan. Sehingga Dinas Perhubungan Kabupaten Bandung Barat merubah desain organisasi menjadi Dinas Perhubungan, Komunikasi dan Informatika Kabupaten Bandung Barat.

Pada dasarnya desain organisai mampu menjadikan sebuah organisasi berjalan sesuai dengan tujuan organisasi yang telah ditetapkan serta mampu menghadapi berbagai hal yang timbul akibat adanya perubahan keorganisasian, oleh karena itu dalam perubahan lebih baik tidak dilakukan secara terpisah. Desain organisasi menjadi sangat penting dan perlu diperhatikan oleh semua komponen organisasi agar berhasil, maka perubahan perlu dilaksanakan secara menyeluruh pada semua askpek organisasi dan penataan desain organisasi merupakan suatu langkah yang perlu dilakukan.

Penelitian ini menggunakan aspekaspek yang harus diperhatikan dalam desain organisasi yang masing-masing aspek siturunkan ke dalam indikatorindikator. Adapun teori yang digunakan dalam penelitian ini adalah model perubahan sudut pandang sistematik untuk melihat desain organisasi.

Untuk memperjelas analisis tentang desain organisasi Dinas Perhubungan Komunikasi dan Informatika, penulis menggunakan aspek-aspek yang diteliti melalui enam aspek desain organisai yang dikemukakan Hellriegel dan Slocum (2007:457) yaitu task, technology, strategic, desain, culture dan people.

\subsection{Task (Deskripsi Kerja)}

Jelaskan akan suatu deskripsi pekerjaan yang diberikan, maka semakin mudah bagi pegawai untuk melaksanakan tugas sesuai dengan tujuan organisasi. Tugas yang bersifat sederhana atau kompleks, bersifat baru atau repetitif, hendaknya distandarisasi, sehingga dapat dipahami, diaplikasikan dengan mudah oleh pegawai yang menjalankan. Pembahasan lebih lanjut mengenai aspek ini terdapat penentuan deskripsi kerja yang diukur oleh 2 unsur yaitu deskripsi kerja bersifat sederhana atau kompleks, dan deskripsi kerja yang jelas dan dapat diaplikasikan oleh pegawai.

Untuk mengukur kedua unsur tersebut, penulis akan memaparkan rincian tugas bidang-bidang yang berada dalam Dinas Perhubungan, Komunikasi dan Informatika Kabupaten Bandung Barat sebagai berikut :

\subsubsection{Bidang Lalu Lintas}

a. Melaksanakan pengkajian bahan perencanaan dan program kerja Bidang Lalu Lintas

b. Melaksanakan pengkajian bahan perumusan kebijakan teknis di bidang manajemen dan rekayasa lalu lintas, keselamatan lalu lintas dan angkutan jalan, pengawasan dan pengendalian lalu lintas dan 
angkutan jalan.

c. Melaksanakan pengkajian bahan perumusan pedoman pelayanan umum di bidang manajemen dan rekayasa lalu lintas, keselamatan lalu lintas dan angkutan jalan, pengawasan dan pengendalian lalu lintas dan angkutan jalan.

d. Melaksanakan pengkajian bahan koordinasi di bidang manajemen dan rekayasa lalu lintas, keselamatan lalu lintas dan angkutan jalan, pengawasan dan pengendalian lalu lintas dan angkutan jalan.

e. Melaksanakan pengkajian bahan pembinaan di bidang manajemen dan rekayasa lalu lintas, keselamatan lalu lintas dan angkutan jalan, pengawasan dan pengendalian lalu lintas dan angkutan jalan.

f. Melaksanakan pengendalian pelaksanaan kebijakan teknis, program kerja dan pelayanan umum di bidang manajemen dan rekayasa lalu lintas, keselamatan lalu lintas dan angkutan jalan, pengawasan dan pengendalian lalu lintas dan angkutan jalan.

g. Melaksanakan pengkajian bahan kerjasama di bidang manajemen dan rekayasa lalu lintas, keselamatan lalu lintas dan angkutan jalan, pengawasan dan pengendalian lalu lintas dan angkutan jalan.

h. Melaksanakan penyusunan telaahan staf sebagai bahan pertimbangan pengambilan kebijakan di bidang manajemen dan rekayasa lalu lintas, keselamatan lalu lintas dan angkutan jalan, pengawasan dan pengendalian lalu lintas dan angkutan jalan.

i. Melaksanakan koordinasi dengan unit kerja terkait.

j. Melaksanakan pengkajian bahan fasilitasi di bidang manajemen dan rekayasa lalu lintas, keselamatan lalu lintas dan angkutan jalan, pengawasan dan pengendalian lalu lintas dan angkutan jalan.

k. Melaksanakan pengendalian ketatausahaan.

1. Melaksanakan monitoring, evaluasi dan pelaporan pelaksanaan program kerja dan tugas di bidang manajemen dan rekayasa lalu lintas, keselamatan lalu lintas dan angkutan jalan, pengawasan dan pengendalian lalu lintas dan angkutan jalan.

m. Melaksanakan tugas lain sesuai dengan tugas pokok dan fungsinya.

\subsubsection{Bidang Angkutan}

a. Melaksanakan pengkajian bahan perencanaan dan program kerja Bidang Angkutan Melaksanakan pengkajian bahan perumusan kebijakan teknis di bidang angkutan orang, angkutan barang dan khusus, angkutan sungai, danau dan penyeberangan.

b. Melaksanakan pengkajian bahan perumusan pedoman pelayanan umum bidang angkutan orang, angkutan barang dan khusus, angkutan sungai, danau dan penyeberangan.

c. Melaksanakan pengkajian bahan koordinasi di bidang angkutan orang, angkutan barang dan khusus, angkutan sungai, danau dan penyeberangan.

d. Melaksanakan pengkajian bahan pembinaan di bidang angkutan orang, angkutan barang dan khusus, angkutan sungai, danau dan penyeberangan.

e. Melaksanakan pengendalian pelaksanaan kebijakan teknis, program kerja dan pelayanan umum di bidang angkutan orang, angkutan barang dan khusus, angkutan sungai, danau dan penyeberangan. 
f. Melaksanakan pengkajian bahan kerjasama di bidangangkutan orang, angkutan barang dan khusus, angkutan sungai, danau dan penyeberangan.

g. Melaksanakan penyusunan telaahan staf sebagai bahan pertimbangan pengambilan kebijakan di bidang angkutan orang, angkutan barang dan khusus, angkutan sungai, danau dan penyeberangan.

h. Melaksanakan koordinasi dengan unit kerja terkait.

i. Melaksanakan pengkajian bahan fasilitasi di bidang angkutan orang, angkutan barang dan khusus, angkutan sungai, danau dan penyeberangan.

j. Melaksanakan pengendalian ketatausahaan.

k. Melaksanakan monitoring, evaluasi dan pelaporan pelaksanaan program kerja dan tugas di bidang angkutan orang, angkutan barang dan khusus, angkutan sungai, danau dan penyeberangan.

1. Melaksanakan tugas lain sesuai dengan tugas pokok dan fungsinya.

\subsubsection{Bidang Teknik Sarana dan Prasarana}

a. Melaksankan pengkajian bahan perencanaan dan program kerja Bidang Teknis Sarana dan Prasarana.

b. Melaksanakan pengkajian bahan perumusan kebijakan teknis di bidang pengelolaan perpakiran, pengelolaan terminal dan perbengkelan.

c. Melaksanakan pengkajian bahan perumusan pedoman pelayanan umum bidang pengelolaan perparkiran, pengelolaan terminal dan perbengkelan.

d. Melaksanakan pengkajian bahan koordinasi di bidang pengelolaan perparkiran, pengelolaan terminal dan perbengkelan.

e. Melaksanakan pengkajian bahan pembinaan di bidang pengelolaan perparkiran, pengelolaan terminal dan perbengkelan.

f. Melaksanakan pengendalian pelaksanaan kebijakan teknis, program kerja dan pelayanan umum di bidangpengelolaan perparkiran, pengelolaan terminal dan perbengkelan.

g. Melaksanakan pengkajian bahan kerjasama di bidang pengelolaan perparkiran, pengelolaan terminal dan perbengkelan.

h. Melaksanakan penyusunan telaahan staf sebagai bahan pertimbangan pengambilan kebijakan di bidang pengelolaan perparkiran, pengelolaan terminal dan perbengkelan.

i. Melaksanakan koordinasi dengan unit kerja terkait.

j. Melaksanakan pengkajian bahan fasilitasi di bidang pengelolaan perparkiran, pengelolaan terminal dan perbengkelan.

k. Melaksanakan pengendalian ketatausahaan.

1. Melaksanakan monitoring, evaluasi dan pelaporan pelaksanaan program kerja dan tugas di bidang pengelolaan perparkiran, pengelolaan terminal dan perbengkelan.

m. Melaksanakan tugas lain sesuai dengan tugas pokok dan fungsinya.

\subsubsection{Bidang Komunikasi dan Informatika}

a. Melaksanakan pengkajian bahan perencanaan dan program kerja Bidang Komunikasi dan Informatika.

b. Melaksanakan pengkajian bahan perumusan kebijakan teknis di bidang posa dan telekomunikasi, sarana komunikasi dan informatika dan 
pengelolaan data elektronik.

c. Melaksanakan pengkajian bahan perumusan pedoman pelayanan umum bidang posa dan telekomunikasi, sarana komunikasi dan informatika dan pengelolaan data elektronik.

d. Melaksanakan pengkajian bahan koordinasi di bidang pos dan telekomunikasi, sarana komunikasi dan informatika dan pengelolaan data elektronik.

e. Melaksanakan pengkajian bahan pembinaan dibidang pos dan telekomunikasi, serta komunikasi dan informatika dan pengelolaan data elekronik.

f. Melaksanakan pengendalian pelaksanaan kebijakan teknis, program kerja dan pelayanan umum di bidangpos dan telekomunikasi, sarana komunikasi dan informatika dan pengelolaan data elektronik.

g. Melaksanakan pengkajian bahan kerjasama di bidangpos dan telekomunikasi, sarana komunikasi dan informatika dan pengelolaan data elektronik.

h. Melaksanakan penyusunan telaahan staf sebagai bahan pertimbangan pengambilan kebijakan di bidang pos dan telekomunikasi, sarana komunikasi dan informatika dan pengelolaan data elektronik.

i. Melaksanakan koordinasi dengan unit kerja terkait.

j. Melaksankan pengkajian bahan fasilitas di bidang pos dan telekomunikasi, sarana komunikasi dan informatika dan pengelolaan data elektronik.

k. Melaksanakan pengendalian ketatausahaan.

1. Melaksanakan monitoring, evaluasi dan pelaporan pelaksanaan program kerja dan tugas di bidang pos dan telekomunikasi, sarana komuniksi dan informatika dan pengelolaan data elektronik.

m. Melaksanakaan tugas lain sesuai dengan tugas pokok dan fungsinya.

Pemaparan deskripsi tugas tersebut didukung oleh pernyataan Sekretaris Dinas Perhubungan, Komunikasi dan Informatika Kabupaten Bandung Barat bahwa ditinjau dari deskripsi kerja bidang perhubungan bersifat sederhana karena itu sistemik. Antar fungsi saling berkaitan termasuk bidang-bidang dibawahnya. Jika disandingkan dengan bidang komunikasi dan informatika maka deskripsi kerja DISHUBKOMINFO menjadi kompleks.

Pada kenyataannya deskripsi kerja dinas bersifat kompleks tetapi rincian tugas yang ada sudah jelas dan relatif mudah dijalankan karena terkendala oleh SDM, dana, budaya, dan sarana prasarana. Selain itu pengaruh perubahan desain organisasi terhadap deskripsi kerja memiliki dampak yang cukup besar terhadap Dinas Perhubungan, Komunikasi dan Informatika.

\subsection{Technology}

Dalam aspek teknologi yang mencakup metode dan teknik serta alatalat yang mendukung jalannya pemerintahan, telah diwujudkan dengan baik oleh Dinas Perhubungan, Komunikasi dan Informatika walaupun terdapat beberapa kendala yang dihadapi. Bidang bidang perhubungan mengakui bahwa hadirnya bidang komunikasi dan informatika memperingan pekerjaan mereka terutama dalam kegiatan yang menyangkut IT.

\subsection{Strategic}

Menganalissi perubahan desain organisasi berpengaruh terhadap startegi Dinas Perhubungan, Komunikasi dan Informatika. Ketika sebelum mengalami perubahan organisasi, fokus tujuan hanya pada bidang perhubungan saja namun saat ini fokus tujuan ditambah dengan bidang 
komunikasi dan informatika. Selain itu deskripsi kerja yang kompleks membuat kegitan-kegiatan organisasi masih dalam proses untuk mencapainnya. Apabila terjadi perubahan strategi organisasi maka akan berpengaruh terhadap desain struktur organisasinya. Hal itu yang sedang dialami oleh Dinas Perhubungan, Komunikasi dan Informatika, adanya perubahan struktur tahun 2012 dari Dinas Perhubungan menjadi Dinas Perhubungan, Komunikasi dan Informatika merupakan suatu respon akan perubahan strategi pelayanan pemerintahan yang ada.

\subsection{Design}

Desain organisasi yang sesuia dengan tuntutan dengan kebutuhan membantu organisasi, oleh karenanya untuk menata sebuah organisasi diperlukan adanya perubahan yang direncanakan, arahnya adalah selalu menuju kepada kondisi yang lebih baik dan efektif dari sebelumnya termasuk didalamnya sebuah penataan atas desain organisasi.

Untuk menciptakan struktur organissi yang sesuai maka pada Tahun 2012 Dinas Perhubungan merubah struktur organisasi menjadi Dinas Perhubungan, Komunikasi dan Informatika. Karena struktur sebelumnya tidak sesuai lagi dengan kebutuhan. Sebuah organisasi tidak boleh bersifat stagnan, melainkan harus bersifat dinamis maka dilakukan perubahan untuk merespon atau menanggapi kehadiran Peraturan Pemerintah Nomor 41 Tahun 2007 dan menanggapi lahirnya reformasi birokrasi.

Aspek desain yang mencakup struktur organisasi yang formal, adanya komunikasi dan koordinasi serta otoritas dan tanggung jawab yang meliputi pengambilan keputusan organisasi masih dirasa kurang pada dinas ini. Berdasarkan observasi dan wawancara, penulis menganalisis bahwa pegabungan bidang perhubungan dengan bidang komunikasi dan informatika pada satu dinas sudah tidak sesuai dengan perkembangan lingkungan yang ada. Dinamika IT semakin cepat sehingga ada tugas dan tuntutan dari masyarakat terhdap bidang komunikasi dan informatika semakin besar. Sekretaris dinas yang sedang mengkaji tentang desain organisai DISHUBKOMINFO saat ini mengakui bahwa lebih baik adanya pemisahan pada kelua bidang tersebut. Selain itu menurut beberapa pegawai dalam berkomunikasi dan berkoordinasi seta dalam pengambilan keputusan lebih berjenjang akibat berokraswi yang bertambah.

\subsection{Culture}

Kesuksesan sebuah organisasi dipengaruhi oleh budaya organisasi sebagai sisitem nilai bersama dalam bentuk karateristik organisasi dengan organisasi lainnya. Budaya organisasi terbangun melalui tahap, pendiri hanya merekrut dan mempertahankan karyawan yang sepikiran dan seperasaan dengan mereka, pendiri melakukan indoktrinasi dan menyosialisasikan cara pikir dan berperilakunya kepada karyawan. pendiri sendiri bertindak sebagai model peran yang mendorong karyawan untuk mengidentifikasi diri dan, dengan demikian, menginternalisasi keyakinan, nilai, dan asumsi pendiri tersebut. Budaya organisasi yang baik hendaknya adaptif dan memiliki etika tinggi.

\begin{tabular}{ccc}
\multicolumn{2}{c}{ Berdasarkan wawancara dan } \\
observasi bidang
\end{tabular}
informatika berusaha beradaptasi dengan budaya bidang perhubungan yang sudah berlaku. Sedangkan pada bidang-bidang perhubungan mempertahankan budaya yang sudah terbentuk. Terlihat dari hasil wawancara dimana yang merasakan pengaruh budaya hanya pada bidang komunikasi dan informatika saja. Pengaruh budaya yang terjadi mencakup cara menanamkan nilai dan keyakinan pegawai serta mempertahankan budaya pada Dinas Perhubungan, 
Komunikasi dan Informatika sudah berjalan cukup baik. Budaya yang ada telah tertanam kuat semenjak dinas ini belum mengalami perubahan organisasi, sehingga membuat bidang komunikasi dan informatika harus beradaptasi dengan budaya yang telah ada karena kekuatan budaya yang dipertahankan pada bidangbidang perhubungan lebih dominan.

\subsection{People}

Perubahan desain organisasi yang dialami oleh Dinas Perhubungan, Komunikasi dan Informatika tentu berpengaruh terhadap sumber daya manusia yang ada. Seperti pada penempatan pegawai pada bidang komunikasi dan informatika setelah mengalami perubahan desain organisasi. Berdasarkan hasil wawancara sekretaris dinas terdapat penarikan pegawai dari satu bidang dan dipindahkan ke bidang yang lain. Namun dengan kemampuan pegawai atau setidaknya pegawai sudah memiliki basic tertentu.

Penulis beranggapan bahwa penarikan pegawai dari satu bidang ke bidang lainnya perlu diperhatikan dari latar belakang pendidikan atau keterampilan yang pegawai miliki, setidaknya pegawai memiliki basic dana danya kemauan untuk belajar. Maka diperlukan peran yang baik untuk membentuk kompetensi yang sesuai dengan kebutuhan organisasi.

\section{KESIMPULAN DAN SARAN}

\subsection{Kesimpulan}

Berdasarkan hasil penelitian dan pembahasan mengenai desain organisasi Dinas Perhubungan, Komunikasi dan Informatika Kabupaten Bandung Barat dengan menggunakan model perubahan dari sudut pandang sistemik Hellriegel dan Slocum, penulis menyimpulkan bahwa perubahan organisasi yang dialami belum terlaksana dengan baik karena masih terdapat beberapa aspek yang belum terpenuhi.
Tugas yang ditinjau dari deskripsi kerja pada Dinas Perhubungan, Komunikasi dan Informatika bersifat kompleks. Hal tersebut terjadi karena perbedaan fungsi antara bidang perhubungan dengan bidang komunikasi dan informatika. Pada kenyataannya deskripsi kerja dinas bersifat kompleks tetapi rincian tugas yang ada sudah jelas dan relatif mudah dijalankan karena terkendala oleh SDM, dana, budaya, dan sarana prasarana. Selain itu pengaruh perubahan desain organisasi terhadap deskripsi kerja memiliki dampak yang cukup besar terhadap Dinas Perhubungan, Komunikasi dan Informatika. Adanya penambahan satu bidang yaitu bidang komunikasi dan informatika yang harus berkerja sama dengan bidang-bidang yang mengurusi perhubungan seperti bidang angkutan, teknik sarana dan prasarana, serta bidang lalu lintas membuat dinas ini lebih dominan pada bidang perhubungan.

Selanjutnya, perubahan strategi pada Dinas Perhubungan, Komunikasi dan Informatika Kabupaten Bandung Barat tentu berpengaruh pada desain organisasi. Perubahan strategi Dinas perhubungan, Komunikasi dan Informatika Kabupaten Bandung Barat dipengaruhi oleh lingkungan internal dan eksternal organisasi tersebut. Apabila terjadi perubahan strategi organisasi maka akan berpengaruh terhadap desain struktur organisasinya. Hal itu yang sedang dialami oleh Dinas Perhubungan, Komunikasi dan Informatika, adanya perubahan struktur tahun 2012 dari Dinas Perhubungan menjadi Dinas Perhubungan, Komunikasi dan Informatika merupakan suatu respon akan perubahan strategi pelayanan pemerintahan yang ada. Namun sejauh ini tujuan, sasaran serta kegiatan-kegiatan yang telah direncanaka sudah dilaksanakn dengan baik.

Desain organisasi Dinas Perhubungan, Komunikasi dan Informatika masih perlu dilakukan pengkajian ulang karena 
perubahan tersebut saat ini sudah tidak sesuai dengan tuntutan perkembangan lingkungan yang ada. Selain itu antara bidang perhubungan dengan bidang komunikasi dan informatika pun memiliki fungsi yang berbeda. Perubahan desain organisasi yang dulu dilakukan oleh Dinas Perhubungan menjadi Dinas Perhubungann, Komunikasi dan Informatika merupakan tanggapan pada Peraturan Pemerintah Nomor 41 tebntang Organisasi Pengangkatan daerah. Dengan demikian aspek desain yang mencakup struktur organisasi yang formail, adanya komunikasi dan koordinasi serta otoritas dan tanggung jawab yang meliputi pengambilan keputusan organisasi masih dirasa kurang pada dinas ini.

Sumber daya manusia yang sesuai kebutuhan serta kemampuan pada dinas perhubungan, komunikasi dan informatika masih kekurangan. Bahkan dalam DISHUBKOMINFO terdapat kepala seksi yang tidak memiliki anggota. Selain itu sumber daya manusia dengan kualifikasi yang baik merupakan salah satu faktor yang mendorong terwujudnya tujuan organisasi. Sejauh ini pelatihan serta pembinaan yang sudah berlangsung memiliki pengaruh besar terhadap kompetensi pegawai Dinas Perhubungan, Komunikasi dan Informatika kareana bidang-bidang yang terdapat pada dinas tersebut merupakan bidang-bidang yang bersentuhan langsung dengan lapangan sehingga memiliki cara dan teknik tertentu. Namun pada kenyataannya pelatihan serta pembinaan tersebut tidak bisa diikuti oleh semua pegawai karena terkendala biaya dan status Pegawai Negeri Sipil.

\subsection{Saran}

1. Peran teknologi yang dilakukan oleh bidang bidang komunikasi dan informatika perlu dirasakan oleh semua dinas-dinas yang berada dalama Pemerintahan Kabupaten
Bandung Barat dan perlu kerja sama yang baik antar SKPD dalam menciptakan $e$ - government seperti pengumpulan data untuk pembaharuan program-program pemerintah yang telah diselenggarakan kepada masyarakat.

2. Desain organisasi pada DISHUBKOMINFO perlu dikaji ulang dan dilakukan restrukurisasi antara bidang perhubungan dengan bidang komuikasi dan informatika. Perkembanagan lingkungan menuntut bidang komunikasi dan informatika untuk berdiri sendiri. Selain itu, pemisahan kedua bidang tersebut akan mempengaruhi deskripsi kerja yang ada, dimana pemisahan bidang akan menyederhanaan tugas-tugas antar bidang dan akan lebih fokus serta terarah serta dilakukan pemetaan karna urusan sudah berbeda.

3. Diperlukan sumber daya manusia baik secara kuantitas maupun kualitas, dimana secara kuantitas penambahan sumber daya manusia sebagai pegawai. Agar tidak ada lagi kepala seksi yang tidak memiliki anggota seperti pada bidang komunikasi dan informatika Sedangkan berdasarkan kualitas dibutuhkan sumber daya manusia yang berkompenten oleh karena itu dibutuhkan pelatihan dan pembinaan secara rutin dan menyeluruh agar menciptakan sumber daya manusia yang memiliki kualifikasi baik.

\section{DAFTAR PUSTAKA}

Creswell, John W. 2013. Research Design: Pendekatan Kulitatif, Kuantitatif dan Mixed. Yogyakarta: Pustaka Pelajar.

Daft, Richard L. 2007. Understanding The

Theory Anda Design Organizations. USA: Thomson Shouth-Western.

Faria Ruhana 2009. Penataan Organisasi 
KPSDMP-KP di Kabupaten Garut, Provinsi Jawa Barat. Institut Pemerintahan Dalam Negeri.

Imelda Tingginehe 2012. Desain Organisasi Badan Penanggulangan Bencana Daerah Kabupaten Kepulauan Talaud Privinsi Sulawesi Utara. Universitas Padjadjaran.

Laporan Akuntabilitas Kinerja Instansi Pemerintaha (LAKIP) Tahun Anggaran 2011 Dinas Perhubungan: Kabupaten Bandung Barat.

Laporan Akuntabilitas Kinerja Instansi

Pemerintaha (LAKIP) Tahun

Anggaran 2014 Dinas Perhubungan, Komunikasi, dan Informatika : Kabupaten Bandung Barat.

Mintzberg, Henry. 1983. Structure In Five : Designing Effective Organization. America : Pretince Hall.

Mohd Husnul 2014 Desain Organisasi Sekretariat daerah Kabupaten Garut. Universitas Padjadjaran.

Nogi, Hessel. 2005. Manajemen

Publik. Jakarta: Grasindo.

Peraturan Pemerintah Republik Indonesia Nomor 41 Tahun 2007 Tentang Organisasi Perangkat Daerah.

Peraturan Daerah Kabupaten Bandung Barat Nomor 5 Tahun 2010 tentang Penyelenggaraan Perhubungan.

Peraturan Daerah Kabupaten Bandung

Barat Nomor 3 Tahun 2012 Tentang

Organisasi Perangkat Daerah.

Robbins, Stephen P. I994. Teori Organisasi : Struktur, Desain dan Aplikasi. Jakarta : ARCAN.

Sedarmayanti. 2009. Manajemen Perkantoran. Bandung:Mandar Maju.

Siagian, Sondang P. 2012. Teori

Pengembangan Organisasi. Jakarta :

Bumi Aksara.

Silalahi, Ulbert. 2011. Studi tentang Ilmu

Administrasi. Bandung : Sinar

Baru Algensindo.

Sugiyono. 2014. Metode Penelitian

Kuantitatif, Kualitatif, dan $R \& D$.

Bandung : ALFABET.
Syarif, Wirman. 2012. Studi tentang Administasi Publik. Jakarta : Erlangga.

Torang, Syamsir. 2012. Organisasi dan Manajemen. Bandung:ALFABET.

Undang-Undang Pemerintahan Daerah No. 23 Tahun 2014 tentang Pemerintahan Daerah.

Weiss, Marco. 2007. Efficient Organizational Design. New York: Palgrave MACMILLA.

Widya 2012 Desain Organisasi Dinas Pertanian dan Ketahanan Pangan Kota Bandung. Universitas Padjadjaran 